\title{
NEXOS ENTRE GESTÃO, AVALIAÇÃO E O ÍNDICE DE DESENVOLVIMENTO DA EDUCAÇÃO BÁSICA (IDEB) EM ESCOLAS PÚBLICAS
}

\author{
ENLACES ENTRE GESTIÓN, EVALUACIÓN Y EL ÍNDICE DE DESARROLLO \\ EDUCATIVO BÁSICO (IDEB) EN LAS ESCUELAS PÚBLICAS
}

\section{LINKS BETWEEN MANAGEMENT, EVALUATION AND THE BASIC EDUCATION DEVELOPMENT INDEX (IDEB) IN PUBLIC SCHOOLS}

\author{
Cristiane Regina Dourado VASCONCELOS ${ }^{1}$ \\ Ione Oliveira Jatobá LEAL ${ }^{2}$ \\ Jomária Alessandra Queiroz de Cerqueira ARAUJO ${ }^{3}$
}

RESUMO: Este artigo foi composto a partir da pesquisa sobre a gestão em escola pública de Salvador/Ba, com ênfase na avaliação da aprendizagem, pela Universidade do Estado da Bahia (UNEB). A referida pesquisa foi desenvolvida no Programa de Mestrado Profissional em Gestão e Tecnologias Aplicadas à Educação (GESTEC) em parceria com o Núcleo de Gestão Educacional e Formação de Gestores (NUGEF), e foi constituída por um arcabouço teórico sobre a avaliação, gestão e desempenho escolar, com ênfase no Índice de Desenvolvimento da Educação Básica (IDEB). Consubstanciados nesse arcabouço, desenvolvemos este artigo, cuja finalidade se destina a contribuir com as reflexões sobre as políticas de avaliação da aprendizagem, sobretudo, o IDEB e suas implicações na escola pública. Destacamos, para tal fim, algumas pesquisas que abordam essa temática a fim de subsidiar outras pesquisas que estão voltadas para estes campos de estudos.

PALAVRAS-CHAVE: Avaliação. Gestão escolar. Desempenho. IDEB.

RESUMEN: Este artículo fue compuesto de una investigación sobre la gestión de escuelas públicas en Salvador / Ba, con énfasis en la evaluación del aprendizaje realizada por la Universidad Estatal de Bahía (UNEB). Esta investigación se desarrolló en el Programa de Maestría Profesional en Gestión y Tecnologías Aplicadas a la Educación (GESTEC) en asociación con el Centro de Gestión Educativa y Capacitación de Gerentes (NUGEF), y estuvo constituida por un marco teórico sobre evaluación, gestión y desempeño. con énfasis en el Índice de Desarrollo de Educación Básica (IDEB). Basado en este marco, desarrollamos este artículo, cuyo propósito es contribuir a las reflexiones sobre las políticas de evaluación del aprendizaje, especialmente IDEB y sus implicaciones para las escuelas públicas. Con este fin,

${ }^{1}$ Universidade do Estado da Bahia (UNEB), Salvador - Bahia - Brasil. Pesquisadora, Núcleo de Gestão Educacional e Formação de Gestores (NUGEF). ORCID: https://orcid.org/0000-0003-4258-7375. E-mail: dourado.cris@gmail.com

${ }^{2}$ Universidade do Estado da Bahia (UNEB), Salvador - Bahia - Brasil. Professora assistente, departamento de Ciências Humanas. Pesquisadora, Núcleo de Gestão Educacional e Formação de Gestores (NUGEF). ORCID: https://orcid.org/0000-0003-3653-0268. E-mail: ionejatoba@gmail.com

3 Universidade do Estado da Bahia (UNEB), Salvador - Bahia - Brasil. Pesquisadora, Núcleo de Gestão Educacional e Formação de Gestores (NUGEF). ORCID: https://orcid.org/0000-0002-8046-3018. E-mail: akeiroz@gmail.com 
destacamos algunas investigaciones que abordan este tema con el fin de subsidiar otras investigaciones que se centran en el campo de estudio.

PALABRAS CLAVE: Evaluación. Gestión escolar. Rendimiento. IDEB.

ABSTRACT: This article was composed from research on public school management in Salvador/Ba, with emphasis on learning assessment by the State University of Bahia (UNEB). This research was developed in the Professional Master Program in Management and Technologies Applied to Education (GESTEC) in partnership with the Center for Educational Management and Training of Managers (NUGEF), and was constituted by a theoretical framework on assessment, management and performance. with emphasis on the Basic Education Development Index (IDEB). Consubstanciados nesse arcabouço, desenvolvemos este artigo, cuja finalidade se destina a contribuir com as reflexões sobre as políticas de avaliação da aprendizagem, sobretudo, o IDEB e suas implicações na escola pública. Destacamos, para tal fim, algumas pesquisas que abordam essa temática a fim de subsidiar outras pesquisas que estão voltadas para campo de estudos.

KEYWORDS: Evaluation. School management. Performance. IDEB.

\section{Introdução}

A avaliação da educação básica tem sido tema central, tanto no que se refere à definição de políticas públicas e às tendências na construção científica de seus processos e resultados, quanto às suas implicações com a gestão escolar e com os profissionais da escola. No centro desse cenário, encontra-se a questão da qualidade da escola pública. Sumariamente, podemos considerar que uma escola de qualidade é caracterizada por vários fatores que podem ser evidenciados para além dos resultados apresentados em testes padronizados (COELHO, 2008; CARDELLI; ELLIOT, 2012).

Cabe sublinhar que a busca incansável pela qualidade da educação brasileira pode ser considerada como um dos elementos que motivam a implementação de políticas públicas educacionais e o incremento de processos de avaliação. Nesse sentido, gestão democrática, processos de avaliação e qualidade do ensino se constituem como elementos centrais na ação do Estado na educação básica brasileira (WERLE, 2011).

No campo das políticas de avaliação, a Lei de Diretrizes e Bases da Educação Nacional (LDBEN, 9.394/96), indica prioridades no sentido de alcançar a melhoria da qualidade do ensino com a adoção do sistema de avaliação nacional do rendimento escolar. Desse modo, o inciso VI, do artigo $9^{\circ}$, da referida Lei, apresenta a avaliação externa como um meio para alcançar tal fim, conforme descrito: “assegurar processo nacional de avaliação do rendimento escolar 
no ensino fundamental, médio e superior, em colaboração com os sistemas de ensino, objetivando a definição de prioridades e a melhoria da qualidade do ensino (BRASIL, 1996, s/p).

Em geral, a criação das avaliações externas se justifica pela necessidade de obter informações sobre o desempenho e os resultados dos sistemas educativos para gestores educacionais e de ensino, famílias e sociedade. A divulgação dos resultados dessas avaliações, possibilita aos diversos segmentos da sociedade perceber como está a qualidade da educação no País.

Um sistema educacional que apresenta alto índice de reprovação e abandono não é desejável. Por outro lado, um sistema em que todos os alunos concluem os estudos, mas não aprendem, também não pode ser considerado eficaz. Sob essa premissa, torna-se relevante conhecer os dados da realidade educacional, a fim de analisar o ensino público brasileiro e assim promover políticas públicas que visem melhorar a qualidade do ensino e da aprendizagem no país. Um sistema ideal, de acordo Fernandes (2007, p. 7) deve ser "aquele no qual todas as crianças e adolescentes tivessem acesso à escola, não desperdiçassem tempo com repetências, não abandonassem os estudos precocemente e, ao final de tudo, aprendessem".

Na busca pela melhoria do sistema educacional, é importante observar que a avaliação vem incorporando novos objetivos e finalidades, a fim de se adequarem à nova dinâmica de reformas educacionais propostas por agências multilaterais (Banco Mundial, Fundo Monetário Internacional, OCDE etc.).

Seguindo padrões internacionais, a avaliação da educação básica é concebida, aplicada e organizada pelo Instituto Nacional de Estudos e Pesquisas Educacionais Anísio Teixeira (INEP). Para obter informações e acompanhamento sobre o desempenho dos sistemas educacionais e especialmente das escolas, o INEP implantou o Sistema de Avaliação da Educação Básica (SAEB), em 1990 (NOVAES; CARNEIRO, 2012).

Desde então, o INEP vem produzindo indicadores sobre o sistema educacional brasileiro, a exemplo do Índice de Desenvolvimento da Educação Básica (IDEB). Alguns desses indicadores, como os índices de evasão e repetência, apontavam para problemas graves na eficiência do ensino oferecido pelas escolas brasileiras, especialmente no que tange aos baixos desempenhos em leitura demonstrados pelos alunos das escolas públicas. Os resultados apresentados pelo IDEB, de alguma forma, têm impactado nos governos federal, estadual e municipal no sentido de reverter o quadro de resultados negativos da educação.

Uma das iniciativas do Governo Federal consistiu na ampliação do ensino fundamental de oito para nove anos, conforme a Lei ${ }^{\circ} 11.274$ de 6 de fevereiro de 2006, alterando a LDB. 
Com essa medida, ficou estabelecida a entrada das crianças de seis anos de idade no ensino obrigatório.

Os objetivos dessa iniciativa destinaram-se a: (I) melhorar as condições de equidade e de qualidade da Educação Básica; (II) estruturar um novo Ensino Fundamental para que as crianças prossigam nos estudos alcançando maior nível de escolaridade; (III) assegurar que, ingressando mais cedo no sistema de ensino, as crianças tenham um tempo mais longo para as aprendizagens da alfabetização e do letramento.

Além dessa iniciativa, o MEC emitiu o Decreto $N^{\circ}$ 6.094, de 24 de abril de 2007, destinado à implementação do Plano de Metas Compromisso Todos pela Educação, conforme segue:

Dispõe sobre a implementação do Plano de Metas Compromisso Todos pela Educação, pela União Federal, em regime de colaboração com Municípios, Distrito Federal e Estados, e a participação das famílias e da comunidade, mediante programas e ações de assistência técnica e financeira, visando a mobilização social pela melhoria da qualidade da educação básica (BRASIL, $2007, \mathrm{~s} / \mathrm{p})$.

Um dos dispositivos desse Plano expressa a necessidade de alfabetizar as crianças até o máximo de oito anos de idade. A partir de então, o MEC implementou também o Pacto Nacional pela Alfabetização na Idade Certa (PNAIC) ${ }^{4}$, um compromisso formal assumido pelos Governos Federal, Distrito Federal, estados e municípios, a fim de assegurar que todas as crianças estejam alfabetizadas até o final do $3^{\circ}$ ano do Ensino Fundamental. Ao aderir ao Pacto, os entes governamentais comprometem-se a:

- Alfabetizar todas as crianças em Língua Portuguesa e em Matemática.

- Realizar avaliações anuais universais, aplicadas pelo INEP, junto aos concluintes do $3^{\circ}$ ano do ensino fundamental. No caso específico dos estados, estes devem apoiar os municípios que tenham aderido às Ações do Pacto para sua efetiva implementação.

\section{Gestão Escolar e os resultados das avaliações - Algumas considerações}

As avaliações em larga escala se destinam a produzir diagnósticos, em nível macro, sobre a qualidade da educação no País. Esses diagnósticos podem ser considerados como

${ }^{4}$ Cf.Pacto Nacional pela Alfabetização na Idade Certa (PNAIC). Disponível em: http://pacto.mec.gov.br/o-pacto. Acesso em: 10 dez. 2018. 
suporte para que os gestores educacionais tomem decisões e acompanhem os efeitos das políticas educacionais voltadas para melhorar a qualidade da educação.

Evidentemente que, mesmo antes da implantação das avaliações externas, tanto gestores educacionais quanto escolares sempre precisavam tomar decisões e iniciativas em prol de questões voltadas ao funcionamento das escolas, formação de professores e, principalmente, acompanhamento da aprendizagem dos alunos. Contudo, o acesso aos diagnósticos sobre a qualidade da educação oferecida pela União, estados e escolas pode ser visto como um elemento importante na história educacional.

Esses diagnósticos funcionam como importante fonte de informação para os gestores das redes de ensino, secretários de educação, gestores escolares e, também, para professores. Para estes últimos, os resultados apresentados nas avaliações externas, analisados conjuntamente com os resultados das avaliações internas, podem servir como incentivo para a mudança de práticas pedagógicas.

Corroborando essa afirmação, os pesquisadores Franco, Alves e Bonamino (2007) defendem que as avaliações nacionais têm limitações para a investigação de efeitos causais, mas consideram inegável que os dados da avaliação em larga escala oferecem oportunidades para que se possam investigar os efeitos de políticas e práticas educacionais.

Os resultados dessas avaliações não apontam soluções para os problemas vivenciados na escola, mas podem ajudar os agentes educacionais a identificarem esses problemas e, a partir daí, buscarem soluções.

A forma de condução da gestão escolar, por exemplo, pode favorecer a criação de processos de avaliação e acompanhamento que tenham como consequência alcançar melhores resultados escolares. No que se refere às políticas de avaliação, a gestão das escolas também passa a exercer um papel relevante no que se refere ao acompanhamento dessas políticas, bem como das ações desenvolvidas nas escolas relativas à avaliação da aprendizagem, monitoramento dos resultados e tomada de decisões. A seguir apresentamos um quadro síntese sobre algumas pesquisas que visam explorar as políticas nacionais de avaliação e a gestão escolar. 
Quadro 1 - Pesquisas que tratam sobre Políticas nacionais de Avaliação e Gestão Escolar Publicações de 2008 a 2013.

\begin{tabular}{|c|c|}
\hline ESTUDOS & OBJETIVOS \\
\hline $\begin{array}{l}\text { Avaliação em educação: uma discussão } \\
\text { de algumas questões críticas e desafios a } \\
\text { enfrentar nos próximos anos (Artigo) } \\
\text { (FERNANDES, 2013) Revista Ensaio - } \\
\text { Rio de janeiro }\end{array}$ & $\begin{array}{l}\text { Apresenta uma discussão sobre quatro questões críticas da } \\
\text { avaliação: a) avaliação formal e informal; b) a avaliação como } \\
\text { (trans) disciplina; c) avaliação e qualidade; e d) avaliação e } \\
\text { discernimento pragmático. A finalidade foi contribuir para } \\
\text { desenvolver práticas de avaliação que possam responder melhor aos } \\
\text { desafios dos sistemas educacionais. }\end{array}$ \\
\hline $\begin{array}{l}\text { Avaliação externa e gestão escolar: } \\
\text { reflexôes sobre usos dos resultados } \\
\text { (Artigo) (MACHADO, 2012) Revista } \\
\text { @ mbienteeducação - São Paulo }\end{array}$ & $\begin{array}{l}\text { O artigo aborda e problematiza usos dos resultados de avaliações } \\
\text { externas no trabalho pedagógico para melhorar a qualidade do } \\
\text { ensino por equipes da gestão escolar no ensino fundamental. Explora } \\
\text { as relações da avaliação externa e da gestão escolar com usos dos } \\
\text { resultados. }\end{array}$ \\
\hline $\begin{array}{l}\text { Políticas de avaliação em larga escala na } \\
\text { educação básica: do controle de } \\
\text { resultados à intervenção nos processos } \\
\text { de operacionalização do ensino (Artigo) } \\
\text { (WERLE, 2011) Revista Ensaio - Rio } \\
\text { de janeiro }\end{array}$ & $\begin{array}{l}\text { Esse artigo discute o panorama da educação brasileira, destacando } \\
\text { os processos de avaliação em larga escala implementados nas } \\
\text { décadas de } 1990 \text { e } 2000 \text {. Faz referência aos três níveis (federal, } \\
\text { estadual, municipal) em que essas avaliações operam e sua } \\
\text { abrangência, desde os segmentos iniciais da educação básica até a } \\
\text { pós-graduação. Analisa os últimos cinco anos como fase de síntese, } \\
\text { estruturação e consolidação de um quadro geral de ação política } \\
\text { referente a processos externos de avaliação em larga escala no } \\
\text { Brasil. }\end{array}$ \\
\hline $\begin{array}{l}\text { Sistemas municipais de ensino: limites e } \\
\text { possibilidades em sua articulação com } \\
\text { as políticas nacionais de avaliação } \\
\text { educacional (Tese de doutorado) } \\
\text { (AROSA, 2013) Universidade Federal } \\
\text { de Juiz de Fora (UFJF) }\end{array}$ & $\begin{array}{l}\text { A pesquisa buscou conhecer como os sistemas municipais de ensino } \\
\text { têm sido afetados pelas políticas do governo federal. A questão } \\
\text { central é a implementação da política nacional para a avaliação } \\
\text { educacional no ensino fundamental municipal e seus possíveis } \\
\text { efeitos. O objetivo geral centrou-se na compreensão sobre como os } \\
\text { sistemas municipais que adotam o ensino fundamental em regime } \\
\text { disseriado têm incorporado as práticas discursivas da política } \\
\text { nacional para a avaliação da educação básica. Os resultados da } \\
\text { pesquisa apontam para mudanças discursivas na avaliação } \\
\text { educacional municipal, favorecidas pela cultura de avaliação e de } \\
\text { monitoramento dos resultados. }\end{array}$ \\
\hline $\begin{array}{l}\text { Três gerações de avaliação da educação } \\
\text { básica no Brasil: interfaces com o } \\
\text { currículo da/na escola (Artigo) } \\
\text { (BONAMINO; SOUSA, 2012) Revista } \\
\text { Educação e Pesquisa - São Paulo }\end{array}$ & $\begin{array}{l}\text { Esse artigo analisa três gerações de avaliação da educação em larga } \\
\text { escala, a partir dos objetivos e desenhos usuais em iniciativas } \\
\text { implementadas no Brasil. Tomando como parâmetro de análise os } \\
\text { objetivos e desenhos dessas avaliações, bem como os estudos e } \\
\text { pesquisas que produziram evidências sobre o tema, exploram-se } \\
\text { possíveis implicações para o currículo escolar. }\end{array}$ \\
\hline $\begin{array}{l}\text { Vinte anos de avaliação da educação } \\
\text { básica no Brasil: aprendizagens e } \\
\text { desafios (Artigo) (COELHO, 2008) } \\
\text { Revista Ensaio - Rio de Janeiro }\end{array}$ & $\begin{array}{l}\text { O artigo analisa como a avaliação nacional da educação escolar } \\
\text { básica se insere historicamente na administração do sistema } \\
\text { educacional brasileiro, de modo articulado à construção científica } \\
\text { dos fatores de qualidade, eficiência, equidade e produtividade. }\end{array}$ \\
\hline
\end{tabular}

Fonte: Retirado de Vasconcelos (2016, p. 44-45).

Algumas pesquisas evidenciam que existe influência da gestão escolar nos desempenhos escolares, sendo possível confirmar a relação existente entre as variáveis de gestão e as práticas avaliativas ocorridas na escola. Tais pesquisas confirmam também que há forte influência na forma de gerir a escola, seus aspectos organizacionais, clima escolar, bem como no desempenho dos alunos. Podemos considerar que existe uma relação positiva entre a forma como ocorre o processo de gestão nos âmbitos administrativo, financeiro e pedagógico das escolas e o desempenho escolar (LIMA, 2011; CUNHA, 2012; MESQUITA, 2009; MUTIM; FREITAS, 2001). 
Com efeito, os problemas da educação básica no Brasil, no que se refere aos altos índices de reprovação e evasão escolar, tornaram-se mais evidentes. Isso porque os resultados insatisfatórios passaram a alimentar polêmicas acerca das políticas públicas e da gestão educacional em diferentes espaços, sobretudo, na mídia. Essa situação assume contornos diferentes quando compreendemos os caminhos com os quais a avaliação se inseriu historicamente na gestão do sistema educacional brasileiro. A avaliação se firma cada vez mais como elemento da regulação e da administração gerencial e competitiva (COELHO, 2008; CARDELLI; ELLIOT, 2012). Nesse sentido:

Esta dinâmica constituída por mecanismos de avaliação, informação e responsabilização através de índices observados e projetados em avaliação externa, ganha sentido de accountability na medida em que, interdependentes, assumem sentidos de monitoramento e controle (AROSA, 2013, p. 184).

A avaliação vem proporcionando uma condição de informação sobre o estado das coisas, fornecendo dados no sentido de prestar contas à sociedade sobre a situação da educação brasileira. Para os gestores escolares, possibilita melhores condições para a tomada de decisão, à medida que estes podem se apropriar dos dados obtidos para a análise e o replanejamento de ações nas escolas.

Os resultados da Prova Brasil, por exemplo, produzem informações a respeito do ensino oferecido por município e escola, com o objetivo de auxiliar os governantes nas decisões sobre o direcionamento de recursos técnicos e financeiros e no estabelecimento de metas e implantação de ações pedagógicas e administrativas que visem à melhoria da qualidade do ensino. De outra parte, pode-se considerar que esses resultados podem funcionar como um elemento de pressão, para pais e responsáveis, pela melhoria da qualidade da educação de seus filhos, uma vez que, a partir da divulgação dos resultados, eles podem cobrar providências para que a escola melhore (BONAMINO, 2012; SOUSA, 2007).

Certamente, as informações coletadas e divulgadas pelo INEP se constituem em elementos imprescindíveis para a gestão da educação nacional, contudo, o sentido dessas informações é desencadear outras etapas necessárias para a efetivação da avaliação externa: quando diretores e coordenadores escolares se apropriam dos dados coletados, interpretandoos e fazendo uso dos resultados no trabalho das escolas.

Os dados disponibilizados pelo INEP podem contribuir para uma reflexão sobre todas as áreas de atuação da gestão escolar, mas devem, principalmente, servir a uma análise sobre a efetiva condução da escola na realização da sua função social na sociedade democrática, que é a de garantir o ensino e a aprendizagem para todos os seus alunos (MACHADO, 2012). 
O benefício das avaliações externas para as escolas consiste em que seus resultados sirvam como modelo ou base de reflexão para gestores, professores, alunos, pais e demais envolvidos da comunidade escolar. O conhecimento preciso dos resultados das avaliações de desempenho serve para fornecer feedback ${ }^{5}$ aos alunos e propiciar ganhos de aprendizagem (FONTANIVE, 2013). Além desse retorno, os resultados podem inspirar novas práticas pedagógicas, replanejando e estabelecendo novas ações que possam conduzir a aprendizagem dos alunos e, consequentemente, a melhoria dos resultados da escola.

De acordo com Fernandes (2013), a avaliação é um domínio fundamental do conhecimento. Essa assertiva se apoia na compreensão de que a avaliação possibilita formular juízos acerca dos fenômenos sociais. Nessa perspectiva, os gestores escolares ficam expostos a um processo de responsabilização pelos resultados das suas escolas.

\section{O Índice de Desenvolvimento da Educação Básica (IDEB)}

O IDEB foi criado em 2007, pelo INEP, como parte do Plano de Desenvolvimento da Educação $(\mathrm{PDE})^{6}$. Esse índice pode ser considerado como um indicador de monitoramento e de qualidade educacional, que relaciona as informações de dois outros indicadores: rendimento escolar e desempenho acadêmico.

Esse índice foi formulado para medir a qualidade do aprendizado nacional e estabelecer metas para a melhoria do ensino. Os dados sobre aprovação são retirados do Censo Escolar e, sobre o desempenho, das notas obtidas em exames padronizados, como a Prova Brasil e o SAEB.

A combinação entre dados de fluxo e desempenho pode possibilitar aos profissionais de uma instituição de ensino reflexões sobre os processos pedagógicos, para que não se dê ênfase a um ou outro desses indicadores - ou seja, se uma escola aprova seus alunos sem que eles aprendam, isso não necessariamente implicará em aumento do IDEB, caso esses alunos não venham a ter sucesso nos testes padronizados. Do mesmo modo, se uma equipe escolar trabalha em função de elevar a proficiência nos testes e não se preocupa com as taxas de evasão, por exemplo, isso também poderá gerar baixos resultados no IDEB (CUNHA, 2012).

O Decreto 6.094, de 24 de abril de 2007, dispõe sobre a implementação do Plano de Metas Compromisso Todos pela Educação, pela União Federal, em regime de colaboração com

5 "Informação comunicada ao aprendiz com o objetivo de modificar seu pensamento ou comportamento para promover a aprendizagem" (SHUTE, 2007 apud FLUMINHAN; ARANA; FLUMINHAN, 2013, p. 723).

${ }^{6}$ O PDE é um plano coletivo de médio e de longo prazo, sistêmico, cujo objetivo é melhorar a qualidade da educação no País, com foco prioritário na educação básica.

RPGE- Revista on line de Política e Gestão Educacional, Araraquara, v. 24 n. 1, p. 55-70, jan./abr., 2020. e-ISSN: 1519-9029. 
municípios, Distrito Federal e estados, e a participação das famílias e da comunidade, mediante programas e ações de assistência técnica e financeira que visem a mobilização social pela melhoria da qualidade da educação básica. O capítulo II desse decreto é destinado especificamente ao IDEB, constando que:

Art. $3^{\circ}$ - A qualidade da educação básica será aferida, objetivamente, com base no IDEB, calculado e divulgado periodicamente pelo INEP, a partir dos dados sobre rendimento escolar, combinados com o desempenho dos alunos, constantes do censo escolar e do Sistema de Avaliação da Educação Básica SAEB, composto pela Avaliação Nacional da Educação Básica - ANEB e a Avaliação Nacional do Rendimento Escolar (Prova Brasil) (BRASIL, 2007, $\mathrm{s} / \mathrm{p})$.

De modo complementar, o PDE colocou à disposição dos estados, municípios e Distrito Federal, instrumentos eficazes de avaliação e implementação de políticas de melhoria da qualidade da educação, sobretudo da educação básica pública.

A partir da análise do IDEB, o MEC ofereceu apoio técnico e financeiro aos municípios com índices insuficientes de qualidade de ensino. $\mathrm{O}$ aporte de recursos se deu a partir da adesão ao Compromisso Todos pela Educação ${ }^{7}$ e da elaboração do Plano de Ações Articuladas (PAR) ${ }^{8}$.

Os sistemas municipais e estaduais que fizeram adesão ao Compromisso devem seguir 28 diretrizes pautadas em resultados de avaliação de qualidade e de rendimento dos estudantes.

O quadro abaixo apresenta a evolução do IDEB do Brasil, com os resultados obtidos por ano de apuração e metas projetadas pelo MEC, permitindo analisar esses dados e verificar se as políticas implementadas com vistas à melhoria da qualidade da educação básica no País estão trazendo efeitos positivos.

${ }^{7}$ O Plano de Metas Compromisso Todos pela Educação, um programa estratégico do PDE, instituído pelo Decreto $\mathrm{n}^{\circ}$ 6.094, de 24 de abril de 2007, é a conjugação dos esforços da União, Estados, Distrito Federal e Municípios, em regime de colaboração, das famílias e da comunidade, em proveito da melhoria da qualidade da educação básica. cf. PORTAL MEC. Disponível em: http://portal.mec.gov.br/arquivos/pdf/diretrizes_compromisso.pdf. Acesso em: 20 abr. 2018.

${ }^{8} \mathrm{O}$ PAR resulta do diagnóstico minucioso da realidade educacional local, realizado pelos os estados e municípios, que a partir desse diagnóstico, desenvolvem um conjunto coerente de ações. cf. PORTAL MEC. Disponível em: http://portal.mec.gov.br/arquivos/pdf/diretrizes_compromisso.pdf. Acesso em: 20 abr. 2018. 
Quadro 2 - Resultados do IDEB do Brasil e metas projetadas referentes aos anos iniciais do EF de 2005 a 2017.

\begin{tabular}{|l|c|c|c|c|c|c|c|c|}
\hline \multicolumn{7}{|c|}{ IDEB OBSERVADO } \\
\hline ANOS & $\mathbf{2 0 0 5}$ & $\mathbf{2 0 0 7}$ & $\mathbf{2 0 0 9}$ & $\mathbf{2 0 1 1}$ & $\mathbf{2 0 1 3}$ & $\mathbf{2 0 1 5}$ & $\mathbf{2 0 1 7}$ \\
\hline TOTAL & 3,8 & 4,2 & 4,6 & 5,0 & 5,2 & \multicolumn{1}{c|}{5,5} & 5,8 \\
\hline \multicolumn{7}{|c|}{ DEPENDÊNCIA ADMINISTRATIVA } \\
\hline ESTADUAL & 3,9 & 4,3 & 4,9 & 5,1 & 5,4 & 5,8 & 6,0 \\
\hline MUNICIPAL & 3,4 & 4,0 & 4,4 & 4,7 & 4,9 & 5,3 & 5,6 \\
\hline PRIVADA & 5,9 & 6,0 & 6,4 & 6,5 & 6,7 & 6,8 & 7,1 \\
\hline PÚBLICA & 3,6 & 4,0 & 4,4 & 4,7 & 4,9 & 5,3 & 5,5 \\
\hline \multicolumn{7}{|c|}{ METAS PROJETADAS } \\
\hline ANOS & $\mathbf{2 0 0 7}$ & $\mathbf{2 0 0 9}$ & $\mathbf{2 0 1 1}$ & $\mathbf{2 0 1 3}$ & $\mathbf{2 0 1 5}$ & $\mathbf{2 0 1 7}$ & $\mathbf{2 0 1 9}$ & $\mathbf{2 0 2 1}$ \\
\hline TOTAL & 3,9 & 4,2 & 4,6 & 4,9 & 5,2 & 5,5 & 5,7 & 6,0 \\
\hline \multicolumn{7}{|c|}{ DEPENDÊNCIA ADMINISTRATIVA } \\
\hline ESTADUAL & 4,0 & 4,3 & 4,7 & 5,0 & 5,3 & 5,6 & 5,9 & 6,1 \\
\hline MUNICIPAL & 3,5 & 3,8 & 4,2 & 4,5 & 4,8 & 5,1 & 5,4 & 5,7 \\
\hline PRIVADA & 6,0 & 6,3 & 6,6 & 6,8 & 7,0 & 7,2 & 7,4 & 7,5 \\
\hline PÚBLICA & 3,6 & 4,0 & 4,4 & 4,7 & 5,0 & 5,2 & 5,5 & 5,8 \\
\hline
\end{tabular}

*Os resultados marcados em verde se referem ao IDEB que atingiu a meta.

Fonte: IDEB - Resultados e Metas (PORTAL INEP, 2019, s/p). Elaborada pela autora.

É possível observar que o País atingiu, em alguns anos, e até mesmo ultrapassou, a meta estipulada pelo MEC para as séries iniciais do EF, com exceção das metas para a rede privada de ensino que, nos anos de 2011, 2013, 2015 e 2017 não conseguiu alcançar a meta estipulada.

No que se refere aos anos finais do EF, a realidade é diferente.

Quadro 3 - Resultados do IDEB do Brasil e metas projetadas, referentes aos anos finais do EF de 2005 a 2017.

\begin{tabular}{|c|c|c|c|c|c|c|c|c|}
\hline \multicolumn{9}{|c|}{ IDEB OBSERVADO } \\
\hline ANOS & & 2005 & 2007 & 2009 & 2011 & 2013 & 2015 & 2017 \\
\hline TOTAL & & 3,5 & 3,8 & 4,0 & 4,1 & 4,2 & 4,5 & 4,7 \\
\hline \multicolumn{9}{|c|}{ DEPENDÊNCIA ADMINISTRATIVA } \\
\hline ESTADUAL & & 3,3 & 3,6 & 3,8 & 3,9 & 4,0 & 4,2 & 4,5 \\
\hline MUNICIPAL & & 3,1 & 3,4 & 3,6 & 3,8 & 3,8 & 4,1 & 4,3 \\
\hline PRIVADA & & 5,8 & 5,8 & 5,9 & 6,0 & 5,9 & 6,1 & 6,4 \\
\hline PÚBLICA & & 3,2 & 3,5 & 3,7 & 3,9 & 4,0 & 4,2 & 4,4 \\
\hline \multicolumn{9}{|c|}{ METAS PROJETADAS } \\
\hline ANOS & 2007 & 2009 & 2011 & 2013 & 2015 & 2017 & 2019 & 2021 \\
\hline TOTAL & 3,5 & 3,7 & 3,9 & 4,4 & 4,7 & 5,0 & 5,2 & 5,5 \\
\hline \multicolumn{9}{|c|}{ DEPENDÊNCIA ADMINISTRATIVA } \\
\hline ESTADUAL & 3,3 & 3,5 & 3,8 & 4,2 & 4,5 & 4,8 & 5,1 & 5,3 \\
\hline MUNICIPAL & 3,1 & 3,3 & 3,5 & 3,9 & 4,3 & 4,6 & 4,9 & 5,1 \\
\hline PRIVADA & 5,8 & 6,0 & 6,2 & 6,5 & 6,8 & 7,0 & 7,1 & 7,3 \\
\hline PÚBLICA & 3,3 & 3,4 & 3,7 & 4,1 & 4,5 & 4,7 & 5,0 & 5,2 \\
\hline
\end{tabular}

* Os resultados marcados em verde se referem ao IDEB que atingiu a meta.

Fonte: IDEB - Resultados e Metas (PORTAL INEP, 2019, s/p). Elaborada pela autora.

Nos anos de 2013, 2015 e 2017 o País não atingiu nenhuma das metas estabelecidas pelo MEC. É possível observar também que, nesse segmento, a rede privada de ensino somente alcançou a meta no ano de 2007. 
A partir desta análise podemos inferir que é necessária uma investigação sobre as causas destes resultados, assim como, investimentos para reverter este panorama.

O panorama do EM é bem parecido com o dos anos finais do EF - nos anos de 2013, 2015 e 2017, nenhuma das metas estabelecidas pelo MEC foi alcançada, por nenhuma das dependências administrativas.

Quadro 4 - Resultados do IDEB do Brasil e metas projetadas, referentes ao Ensino Médio (EM), no período de 2005 a 2017.

\begin{tabular}{|c|c|c|c|c|c|c|c|c|}
\hline \multicolumn{9}{|c|}{ IDEB OBSERVADO } \\
\hline ANOS & & 2005 & 2007 & 2009 & 2011 & 2013 & 2015 & 2017 \\
\hline TOTAL & & 3,4 & 3,5 & 3,6 & 3,7 & 3,7 & 3,7 & 3,8 \\
\hline \multicolumn{9}{|c|}{ DEPENDÊNCIA ADMINISTRATIVA } \\
\hline ESTADUAL & & 3,0 & 3,2 & 3,4 & 3,4 & 3,4 & 3,5 & 3,5 \\
\hline PRIVADA & & 5,6 & 5,6 & 5,6 & 5,7 & 5,4 & 5,3 & 5,8 \\
\hline PÚBLICA & & 3,1 & 3,2 & 3,4 & 3,4 & 3,4 & 3,5 & 3,5 \\
\hline \multicolumn{9}{|c|}{ METAS PROJETADAS } \\
\hline ANOS & 2007 & 2009 & 2011 & 2013 & 2015 & 2017 & 2019 & 2021 \\
\hline TOTAL & 3,4 & 3,5 & 3,7 & 3,9 & 4,3 & 4,7 & 5,0 & 5,2 \\
\hline \multicolumn{9}{|c|}{ DEPENDÊNCIA ADMINISTRATIVA } \\
\hline ESTADUAL & 3,1 & 3,2 & 3,3 & 3,6 & 3,9 & 4,4 & 4,6 & 4,9 \\
\hline PRIVADA & 5,6 & 5,7 & 5,8 & 6.0 & 6,3 & 6,7 & 6,8 & 7,0 \\
\hline PÚBLICA & 3,1 & 3,2 & 3,4 & 3,6 & 4,0 & 4,4 & 4,7 & 4,9 \\
\hline
\end{tabular}

*Os resultados marcados em verde se referem ao IDEB que atingiu a meta.

Fonte: IDEB - Resultados e Metas (PORTAL INEP, 2019, s/p). Elaborada pela autora.

A análise dos quadros 2, 3 e 4 permite afirmar que os resultados obtidos nas séries iniciais do EF são extremamente superiores aos resultados obtidos nas séries finais do EF, assim como no EM. Com exceção das metas projetadas para a rede privada, para os anos de 2011, 2013, 2015 e 2017 que não foram alcançadas, o Brasil apresentou crescimento satisfatório nesse indicador, ultrapassando as metas projetadas já em 2011.

Nas séries finais do EF e no EM, é possível observar que nos anos de 2013, 2015 e 2017 não houve evolução significativa dos resultados, além do que o País não alcançou nenhuma das metas projetadas pelo MEC para aqueles anos.

Essa análise pode levar ao entendimento de que, do ponto de vista do IDEB, muitas ações ainda precisam ser implementadas para, de fato, melhorar a qualidade da educação no País. De modo a contribuir com as reflexões, sistematizamos um quadro contendo pesquisas acerca do desempenho de escolas no IDEB e sua relação com a condução da gestão escolar com os índices observados. 
Quadro 5 - Pesquisas que tratam sobre IDEB e Gestão Escolar - Publicações de 2009 a 2014

\begin{tabular}{|c|c|}
\hline ESTUDOS & OBJETIVOS \\
\hline $\begin{array}{l}\text { A ação gestora e a responsabilização na } \\
\text { educação pública: um estudo de caso em } \\
\text { uma escola do estado do Mato Grosso } \\
\text { (Dissertação de mestrado) (SILVA, } \\
\text { 2014) Universidade Federal de Juiz de } \\
\text { Fora (UFJF) }\end{array}$ & $\begin{array}{l}\text { A dissertação objetivou analisar os fatores que levaram a Escola } \\
\text { Estadual Manuel Bandeira (nome fictício) a modificar sua posição } \\
\text { de uma das escolas de ensino fundamental do município de } \\
\text { Juara/MT, no início da década de 1990, com maiores dificuldades } \\
\text { em termos da qualidade do ensino oferecido e da promoção do } \\
\text { rendimento acadêmico de seus alunos, para a unidade escolar com o } \\
\text { maior IDEB, no ano de } 2011 \text {, do estado do Mato Grosso. }\end{array}$ \\
\hline $\begin{array}{l}\text { Descompassos do índice de } \\
\text { desenvolvimento da educação básica } \\
\text { (Dissertação de mestrado) (SILVA, } \\
\text { 2011) Universidade Federal da Paraíba } \\
\text { (UFPB) }\end{array}$ & $\begin{array}{l}\text { A pesquisa objetivou analisar os descompassos da avaliação } \\
\text { implementada pelo IDEB, partindo dos resultados divulgados pelo } \\
\text { MEC e documentos publicados pela mídia. Uma das questões mais } \\
\text { relevantes é que existe um descompasso entre a teoria do IDEB } \\
\text { proposta pelo governo e a realidade prática, o que prejudica a } \\
\text { veracidade do melhoramento traduzido nos índices numéricos sobre } \\
\text { o ensino público do País. }\end{array}$ \\
\hline 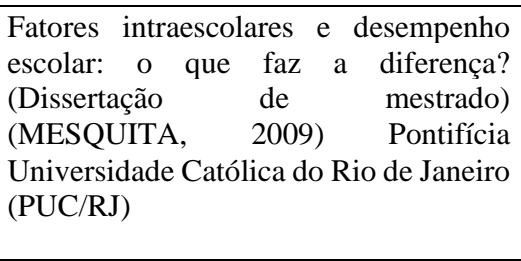 & $\begin{array}{l}\text { O estudo buscou analisar os fatores intraescolares e suas influências } \\
\text { sobre o desempenho dos alunos. A investigação foi desenvolvida em } \\
\text { uma escola pública do Rio de Janeiro que apresentou melhorias nos } \\
\text { resultados escolares, a partir dos dados do IDEB, entre os anos de } \\
2005 \text { e } 2007 \text {. As análises evidenciaram que há forte influência da } \\
\text { gestão e dos aspectos organizacionais na definição do clima escolar } \\
\text { e, consequentemente, no bom desempenho dos alunos. }\end{array}$ \\
\hline $\begin{array}{l}\text { Políticas e gestão pública educacional } \\
\text { em Riachão do Jacuípe, Bahia, Brasil: a } \\
\text { elevação do índice de desenvolvimento } \\
\text { da educação básica-IDEB (Dissertação } \\
\text { de mestrado) (OLIVEIRA, 2011) } \\
\text { Universidade Católica do Salvador } \\
\text { (UCSAL) }\end{array}$ & $\begin{array}{l}\text { O estudo objetivou conhecer as variáveis que, na percepção de atores } \\
\text { e gestores da educação, foram determinantes para o crescimento } \\
\text { positivo nas médias alcançadas a partir da primeira divulgação da } \\
\text { avaliação feita pelo MEC, em 2005, através do IDEB - mais } \\
\text { especificamente nos resultados do IDEB de } 2007 \text { e } 2009 \text { da escola } \\
\text { pública municipal de Ensino Fundamental I Manoel Inácio da Silva, } \\
\text { em Riachão do Jacuípe, Bahia, Brasil. }\end{array}$ \\
\hline
\end{tabular}

Fonte: retirado deVasconcelos (2016, p. 46).

Conforme se pode observar, muitos pesquisadores demonstram interesse quanto à qualidade da educação em nosso país, desenvolvendo pesquisas sobre as temáticas da avaliação, gestão escolar e IDEB. A forma como os processos avaliativos estão sendo conduzidos e acompanhados, dentro das instituições de ensino e no âmbito dos governos, passou a ser objeto de investigação de muitos estudiosos.

A questão envolve a supervalorização de indicadores e resultados acadêmicos quantificáveis e mensuráveis, a despeito de contextos e processos educativos específicos. Com referência ao IDEB, as escolas ficam inseridas em uma relação de valoração e posicionamento do índice alcançado, que é comparado aos índices municipais e nacionais. Em cada período de avaliação, tanto as escolas quanto os sistemas de ensino passam a ser vistos pelo posicionamento de seus índices em relação ao alcançado nacionalmente (COELHO, 2008; AROSA, 2013).

\section{Considerações finais}

Analisando o panorama da educação básica brasileira, pode-se constatar a necessidade 
de a gestão escolar empreender esforços no acompanhamento e no uso dos resultados das avaliações externas como recursos para o estabelecimento de ações pedagógicas.

Em contrapartida, é evidente a necessidade do desenvolvimento de políticas educacionais que invistam na descentralização dos recursos, na construção da autonomia pedagógica e administrativa das escolas, na formação dos professores, na profissionalização da gestão e nas boas condições estruturais e materiais dessas escolas (MESQUITA, 2009).

O exercício de analisar essas pesquisas permitiu compreender que os estudos sobre avaliação não se esgotam aqui. Políticas já foram implementadas. É perceptível uma mudança de visão de gestores educacionais e escolares, bem como de professores, com relação às necessidades de acompanhamento, monitoramento e até mesmo mudança de práticas, mas é fato que, para melhorar a qualidade da educação no País, muitos caminhos ainda devem ser trilhados.

\section{REFERÊNCIAS}

AROSA, D. V. S. Sistemas Municipais de Ensino: limites e possibilidades em sua articulação com as políticas nacionais de Avaliação Educacional. Orientadora: Diva Chaves Sarmento. 2013. 249 f. Tese (Doutorado). Programa de Pós-Graduação em Educação. Juiz de Fora: UFJF, 2013. Disponível em: http://www.ufjf.br/ppge/files/2013/07/TESE-DEIZEAROSA-para-PPGE.pdf. Acesso em: 10 mar. 2020.

BONAMINO, A.; SOUSA, S. Z. Três gerações de avaliação da educação básica no Brasil: interfaces com o currículo da/na escola. Educação e Pesquisa, São Paulo, v. 38, n. 2, p. 373 388, abr./jun. 2012.

BRASIL. Lei n. 9.394 de 20 de dezembro de 1996. Estabelece as Diretrizes e Bases da Educação Nacional. Diário Oficial da União, Brasília, DF, 23 dez. 1996. Disponível em: http://www.planalto.gov.br/ccivil_03/leis/19394.htm. Acesso em: 10 mar. 2020.

BRASIL, Ministério da Educação. Portaria n. 931, de 21 de março de 2005. Institui que Sistema Nacional de Avaliação da Educação Básica será composto por dois processos de avaliação: a Avaliação Nacional da Educação Básica - ANEB, e a Avaliação Nacional do Rendimento Escolar - ANRESC. Brasília, DF, 2005.

BRASIL. Decreto n. 6.094 de 24 de abril de 2007. Dispõe sobre a implantação do Plano de Metas Compromisso Todos pela Educação. Diário Oficial da União, Brasília, DF, 25 abr. 2007a. Disponível em: http://www.planalto.gov.br/ccivil_03/_Ato2007-

2010/2007/Decreto/D6094.htm. Acesso em: 10 mar. 2020.

BRASIL. Ministério da Educação. Plano de Desenvolvimento da Educação (PDE). Brasília, DF, 2007b. 
BRASIL, Ministério da Educação. Portaria n. 482, de 7 de junho de 2013. Dispõe sobre o Sistema de Avaliação da Educação Básica - SAEB. Brasília, DF, 2013.

BRASIL. Portal INEP. IDEB - Resultados e Metas. 2018.

CARDELLI, D. T.; ELLIOT, L. G. Avaliação por diferentes olhares: fatores que explicam o sucesso de escola carioca em área de risco. Ensaio: aval. pol. públ. Educ., Rio de Janeiro, v. 20, n. 77, p. 769-797, out./dez. 2012.

COELHO, M. I. M. Vinte anos de avaliação da educação básica no Brasil: aprendizagens e desafios. Ensaio: aval. pol. públ. educ., Rio de Janeiro, v. 16, n. 59, p. 229-258, abr./jun. 2008 .

CUNHA, E. O. A gestão escolar e sua relação com os resultados do IDEB: um estudo em duas escolas municipais de Salvador. Orientadora: Maria Couto Cunha. 2012. $172 \mathrm{f}$. Dissertação (mestrado). Universidade Federal da Bahia. Faculdade de Educação, Salvador, 2012. Disponível em: http://repositorio.ufba.br/ri/handle/ri/9266. Acesso em: 10 mar. 2020.

FERNANDES, D. Avaliação em Educação: uma discussão de algumas questões críticas e desafios a enfrentar nos próximos anos. Revista Ensaio: aval. pol. públ. educ., Rio de Janeiro, v. 21, n. 78, p. 11-34, jan./mar. 2013.

FERNANDES, R. Índice de Desenvolvimento da Educação Básica (IDEB). Brasília: INEP, 2007.

FLUMINHAN, C. S. L.; ARANA, A. R. A.; FLUMINHAN, A. A importância do feedback como ferramenta pedagógica na educação à distância. Encontro de Ensino, Pesquisa e Extensão, Presidente Prudente, p.721-728, 21 a 24 out. 2013.

FONTANIVE, N. S. A Divulgação dos Resultados das Avaliações dos Sistemas Escolares: limitações e perspectivas. Ensaio: aval. pol. públ. educ., Rio de Janeiro, v. 21, n. 78, p. 83100, jan./mar. 2013.

FRANCO, C.; ALVES, F.; BONAMINO, A. Qualidade do Ensino Fundamental: políticas, suas possibilidades, seus limites. Revista Educação \& Sociedade. Campinas, v. 28, n.100 Especial, p. 989-1014, 2007.

LIMA, E. S. L. O diretor e as avaliações praticadas na escola. Orientadora: Benigna Maria De Freitas Villas Boas. 2011. 277 f. Tese (Doutorado). Programa de Pós-Graduação em Educação, Faculdade de Educação, Universidade de Brasília. Brasília, 2011. Disponível em: https://repositorio.unb.br/bitstream/10482/10108/1/2011_EriseveltonSilvaLima.pdf. Acesso em: 10 mar. 2020.

MACHADO, C. Avaliação Externa e Gestão Escolar: Reflexões sobre usos dos resultados. Revista@mbienteeducação, v. 5, n. 1, p. 70-82, jan./jun. 2012.

MESQUITA, S. S. A. Fatores intraescolares e desempenho escolar: o que faz a diferença? Orientadora: Isabel Alice Oswald Monteiro Lelis. 2009. 126 f. Dissertação (Mestrado). Programa de Pós-Graduação em Educação. Pontifícia Universidade Católica do Rio de 
Janeiro. Rio de Janeiro, 2009. Disponível em: https://www.maxwell.vrac.pucrio.br/14621/14621_1.PDF. Acesso em: 10 mar. 2020.

MUTIM, A. L. B.; FREITAS, K. S. Relação Entre a Gestão Participativa e o Desempenho Escolar. Revista Ensaio: aval. pol. públ. educ., Rio de Janeiro, v. 9, n. 33, p. 489-508, out./dez. 2001.

NOVAES, I. L.; CARNEIRO, B. P. B. In: NOVAES, I. L.; HETKOWSKI, T. M (Org.). Gestão, Tecnologias e Educação: construindo redes sociais. Salvador: Eduneb, 2012.

OLIVEIRA, M. R. C. Políticas e Gestão Pública Educacional em Riachão do Jacuípe, Bahia, Brasil: A elevação do Índice de Desenvolvimento da Educação Básica - IDEB. 2011. 143f. Dissertação (Mestrado). Políticas Públicas e Cidadania. Universidade Católica do Salvador. Salvador, 2011.

SILVA, C. V. A. P. Descompassos do Índice de Desenvolvimento da Educação Básica. Orientador: Luiz Pereira de Lima Júnior. Dissertação. 2011. 100 f. (Mestrado). Universidade Federal da Paraíba. João Pessoa, 2011. Disponível em:

https://repositorio.ufpb.br/jspui/handle/tede/4625. Acesso em: 10 mar. 2020.

SILVA, R. M. C. A ação gestora e a responsabilização na Educação Pública: um estudo de caso em uma escola do Estado do Mato Grosso. Orientador: Lourival Batista de Oliveira Júnior. 2014. 178 f. Dissertação (Mestrado). Programa de Pós-Graduação Profissional em Gestão e Avaliação da Educação Pública, CAED - Centro de Políticas Públicas e Avaliação da Educação, Universidade Federal de Juiz de Fora. Juiz de Fora, 2014. Disponível em: http://www.mestrado.caedufjf.net/wpcontent/uploads/2014/12/Disserta\%C3\%A7\%C3\%A3o_FINAL_-Rosana-Maria-Christofoloda-Silva.pdf. Acesso em: 10 mar. 2020.

SOUSA, S. Z. Avaliação, ciclos e qualidade do Ensino Fundamental: uma relação a ser construída. Estudos avançados. v. 21, n. 60. São Paulo, 2007.

VASCONCELOS, C. R. D. A Criação de um Portal para partilhar experiências da Gestão da Escola Municipal Cidade Vitória da Conquista, Salvador/Ba, com a Avaliação da Aprendizagem. Orientador: Ivan Luiz Novaes. 2016. 110 f. Dissertação (Mestrado). Programa de Pós-Graduação Gestão e Tecnologia Aplicada (GESTEC), Universidade do Estado da Bahia (UNEB). Salvador, 2016. Disponível em: http://www.cdi.uneb.br/site/wpcontent/uploads/2016/08/Cristiane-Dourado.pdf. Acesso em: 10 mar. 2020.

WERLE, F. O. C. Políticas de avaliação em larga escala na educação básica: do controle de resultados à intervenção nos processos de operacionalização do ensino. Ensaio: aval. pol. públ. Educ., Rio de Janeiro, v. 19, n. 73, p. 769-792, out./dez. 2011. 
Como referenciar este artigo:

VASCONCELOS, Cristiane Regina Dourados; LEAL, Ione Oliveira Jatobá; ARAÚJO, Jomária Alessandra de Queiroz Cerqueira. Nexos entre gestão, avaliação e o Índice de Desenvolvimento da Educação Básica (IDEB) em escolas públicas. Revista on line de Política e Gestão Educacional, Araraquara, v. 24 n. 1, p. 55-70, jan./abr., 2020. e-ISSN: 1519-9029. DOI: https://doi.org/10.22633/rpge.v24i1.12865

Submetido em: 18/09/2019

Revisões requeridas: $20 / 11 / 2019$

Aprovado em: 26/12/2019

Publicado em: 06/01/2020 